\title{
How does coarse gravel augmentation affect early-stage Chinook salmon Oncorhynchus tshawytscha embryonic survivorship?
}

\author{
R. M. Utz*†, C. F. Mesick $\$$, B. J. Cardinale§ and T. Dunne* \\ *Bren School of Environmental Science and Management, University of California, Santa \\ Barbara, Santa Barbara, CA 93106, U.S.A., \$Carl Mesick Consultants, 7981 Crystal \\ Boulevard, El Dorado, CA 95623, U.S.A. and §University of Michigan School of Natural \\ Resources and Environment, 440 Church St., Ann Arbor, MI 48109, U.S.A.
}

(Received 16 May 2012, Accepted 24 January 2013)

\begin{abstract}
Early-stage Chinook salmon Oncorhynchus tshawytscha embryos were incubated in artificial redds that mimicked hyporheic conditions in gravel-augmented habitat to assess survivorship. Two complementary experiments were conducted where units varied along gradients of (1) increasing interstitial flow velocity $\left(0.05-2.50 \mathrm{~cm} \mathrm{~s}^{-1}\right)$ in a uniformly coarse (particles $\geq 22 \mathrm{~mm}$ ) sediment mixture and (2) increasing sediment porosity with interstitial flow velocity held constant. Embryonic survivorship increased moderately along a gradient of interstitial flow velocity, while survivorship among units with varying sediment porosities was consistent. No evidence for flow-induced agitation and mortality was observed. Results suggest that high interstitial flow velocities may confer a moderate advantage for incubating salmonid embryos when conditions that typically reduce embryonic mortality (i.e. low concentrations of fine particles) are ideal.

(C) 2013 The Authors

Journal of Fish Biology (c) 2013 The Fisheries Society of the British Isles
\end{abstract}

Key words: California; hyporheic flow; interstitial velocity; porosity; restoration; spawning habitat.

\section{INTRODUCTION}

Populations of anadromous salmonids in western North America have dramatically declined over the past two centuries as a result of a host of anthropogenic stressors, and this has led to management practices that are aimed at recovering stocks (Lach \& Duncan, 2006). One principal factor that is believed to limit salmonid population recovery in many affected systems is the quality of spawning habitat (Ruckelshaus et al., 2002; Honea et al., 2009). Because of this, restoration efforts often focus on augmenting spawning habitat, usually by adding coarse sediments to river channels. Yet, the net effect and efficacy of this management practice is not always clear. Many factors determine the quality of spawning habitat for salmonids, and there is little reason to expect that gravel augmentation should be uniformly positive for all life stages and populations. Optimal particle sizes in redds are known to vary among early life stages (Kondolf, 2000), and populations themselves can exhibit local adaptation

$\uparrow$ Author to whom correspondence should be addressed at present address: National Ecological Observatory Network, $168538^{\text {th }}$ St, Boulder, CO 80301, U.S.A. Tel.: +1 724272 7769; email: utz.ryan@ gmail.com 
to grain sizes (Ramstad et al., 2010; Rollinson \& Hutchings, 2011). Even when considering a single life stage of a focal population, gravel augmentation has potential to alter the benthic environment of a stream in ways that might prove beneficial (e.g . removal of silt) or harmful (e.g. increased access by predators). These contrasting possibilities highlight the need to empirically evaluate the effects of common gravel augmentation practices on the different life-history stages of salmonids.

One overlooked factor that may influence the efficacy of gravel augmentation restoration projects is the potential for early-stage embryos to experience physical disturbance and mortality. During the period prior to eye development, salmonid embryos are highly vulnerable to mechanical shock: a singly applied force equivalent to a $1.3 \mathrm{~cm}$ drop on a hard surface outside of water may induce $>50 \%$ mortality in Chinook salmon Oncorhynchus tshawytscha (Walbaum 1792) embryos (Jensen \& Alderdice, 1989). Course gravel augmentation has the potential to elevate interstitial flow velocities by eliminating the small particles that fill interstitial space and keep velocities low (Malcolm et al., 2008). While removal of small particles (fine sediments) may enhance egg survivorship by increasing dissolved oxygen (DO; Merz \& Setka, 2004), some studies have hypothesized that a complete elimination of small bed materials may damage embryos during sensitive stages of development by inducing higher flow velocity and mechanical agitation (Merz et al., 2004). This hypothesis has yet to be empirically confirmed or refuted.

The goal of this study was to evaluate $O$. tshawytscha embryonic survivorship in redds composed of porous substrata with very high interstitial flow velocities to determine if the potential for embryo agitation requires consideration in restored habitat. Two complementary experiments were conducted on embryos reared within artificial redds where increasing (1) porosity or (2) interstitial flow velocity was hypothesized to reduce $O$. tshawytscha embryo survivorship. The model system used to establish treatment values was a large-scale restoration project in the Merced River, California, U.S.A. (Marshall et al., 2008), currently the southernmost extent of the native $O$. tshawytscha range and site of various habitat enhancement efforts aimed at recovering local threatened stock.

\section{MATERIALS AND METHODS}

\section{MERCED RIVER FIELD MEASUREMENTS}

Prior to setting up the experiments, sediment porosity and interstitial flow velocities were measured in the field where restoration attempts had been made to enhance spawning habitat via gravel augmentation. The goal of recording these measurements was to quantify realistic ranges of the key benthic variables to constrain the experimental manipulations to realistic ranges. Measurements were taken in a reach of the Merced River that had been artificially enhanced to promote $O$. tshawytscha spawning success. Spawning habitat in the Merced River has been degraded by hydraulic and gravel mining, water diversion and the loss of natural sediment delivery caused by impoundments (Kondolf et al., 1996; Harrison et al., 2011).

The focal restoration site was the Merced River Spawning Habitat Enhancement Project (MRSHEP; $37^{\circ} 29^{\prime} \mathrm{N} ; 120^{\circ} 28^{\prime} \mathrm{W}$ ). To enhance the spawning success of a threatened stock of autumn-run $O$. tshawytscha, the MRSHEP included the addition of 1.5 million t of sediment with a median diameter of $58 \mathrm{~mm}$ and no particles $<6 \mathrm{~mm}$ (CDWR, 2001 and unpubl. data). Coarse gravel augmentation similar to that utilized in the MRSHEP is a typical component of salmonid spawning habitat restoration efforts in California (Merz et al., 2004; 
2006; Pasternack, 2008) and elsewhere (Barlaup et al., 2008; Roni et al., 2008). Although environmental conditions, apart from sediment characteristics, may not be conducive to supporting $O$. tshawytscha in the Merced River [such as elevated water temperatures (Vogel, 2003, 2007)], the present focus was on elevated interstitial flow velocities and porosities and therefore variables such as temperature were not considered further for this study.

To characterize the distribution of sediment sizes, bulk sediment samples from four riffles in the MRSHEP and three from upstream of the restoration project were collected in the summer of 2006 (within the MRSHEP reach) or autumn of 2008 (upstream of the MRSHEP reach). Samples were collected approximately midway between the wetted channel boundary and the thalweg. A McNeil sampler (McNeil \& Ahnell, 1964) was used to extract the coarse surface layer and fine sub-surface layers to a depth of $30 \mathrm{~cm}$ (following Bunte \& Abt, 2001). Approximately 441 of sediment per sample were extracted, dried and mechanically sorted in the laboratory using stacked sieves. The cumulative distribution of sediment particle sizes by mass is illustrated in Fig. 1(a).

To quantify interstitial flow velocities, a conductiometric standpipe method (Greig et al., 2005) was employed to estimate flow velocities within gravel beds that were likely to house salmonid redds in the MRSHEP reach. Briefly, the Greig et al . (2005) technique involves burying a standpipe housing a conductivity probe at a set depth in benthic sediments, delivering a pulse of saline solution adjacent to the probe, and comparing the slope of the exponential decay in conductivity over time to laboratory standards recorded in a flume. Results suggested that interstitial flow velocity at a depth of $25 \mathrm{~cm}$ [the typical redd depth for $O$. tshawytscha (DeVries, 1997)] in the MRSHEP reach ranges from undetectable to a maximum of $c .0 .68 \mathrm{~cm} \mathrm{~s}^{-1}$. Such interstitial flow velocities recorded in the MRSHEP reach fell within the range of those observed in other salmonid-supporting rivers. Many have observed interstitial velocities well below $1.0 \mathrm{~cm} \mathrm{~s}^{-1}$ (Greig et al., 2005; Zimmermann \& Lapointe, 2005; Carling et al., 2006). Malcolm et al. (2008) recorded $c .1 .25 \mathrm{~cm} \mathrm{~s}^{-1}$ in a newly constructed artificial Atlantic salmon Salmo salar L. 1758 redd comprised particles $>4 \mathrm{~mm}$, but this value decreased over time as fine sediment accumulated.

\section{EXPERIMENTAL DESIGN}

After field measurements were taken to define the range of variable values (particle size and interstitial flow velocity), two separate laboratory experiments involving $O$. tshawytscha embryo incubation in artificial redds were conducted during the autumn of 2010 to explore how benthic variables influence early-stage survivorship. Conditions within the artificial redds were meant to span and somewhat exceed the range of those observed in the MRSHEP reach. In one experiment, embryos were incubated in redds with uniformly coarse particle mixtures while interstitial flow velocity varied among units to test if high interstitial flows induced agitation and mortality. For the second experiment, sediment porosity varied among units (artificial redds) with interstitial velocities held constant to determine if high porosity promotes mortality associated with movement and agitation. Two successive trials of each experiment were conducted. Each experiment included 12 levels of the variable of interest (i.e. interstitial flow velocity or porosity) with one replicate per level (i.e. a regression design). For the second trial of both experiments, interstitial velocities were increased to expand the range of conditions tested. Interstitial flow velocities and porosity values for each experiment and trial are listed in Table I.

In the first experiment, termed the 'variable flow velocity experiment', embryos were incubated in a uniformly coarse sediment mixture and interstitial velocities varied among treatments. One goal for this experiment was to incubate all the embryos in a sediment mixture porous enough to permit embryo mobility while, at the same time, not too porous such that embryos immediately sunk to the bottom of the artificial redds. Preliminary trials with sterile embryos suggested that embryos readily moved through interstitial spaces in sediment mixtures consisting of $\geq 22.4 \mathrm{~mm}$ particles when interstitial velocities were extremely high (c. $16.4 \mathrm{~cm} \mathrm{~s}^{-1}$ ), thus particles in all variable flow velocity experiment redds were $\geq 22.4 \mathrm{~mm}$. Applied interstitial water velocity treatments in this mixture ranged from 0.05 to 1.00 and 0.18 to $2.35 \mathrm{~cm} \mathrm{~s}^{-1}$ in the first and second trials, respectively (Table I). Discharge was recorded 

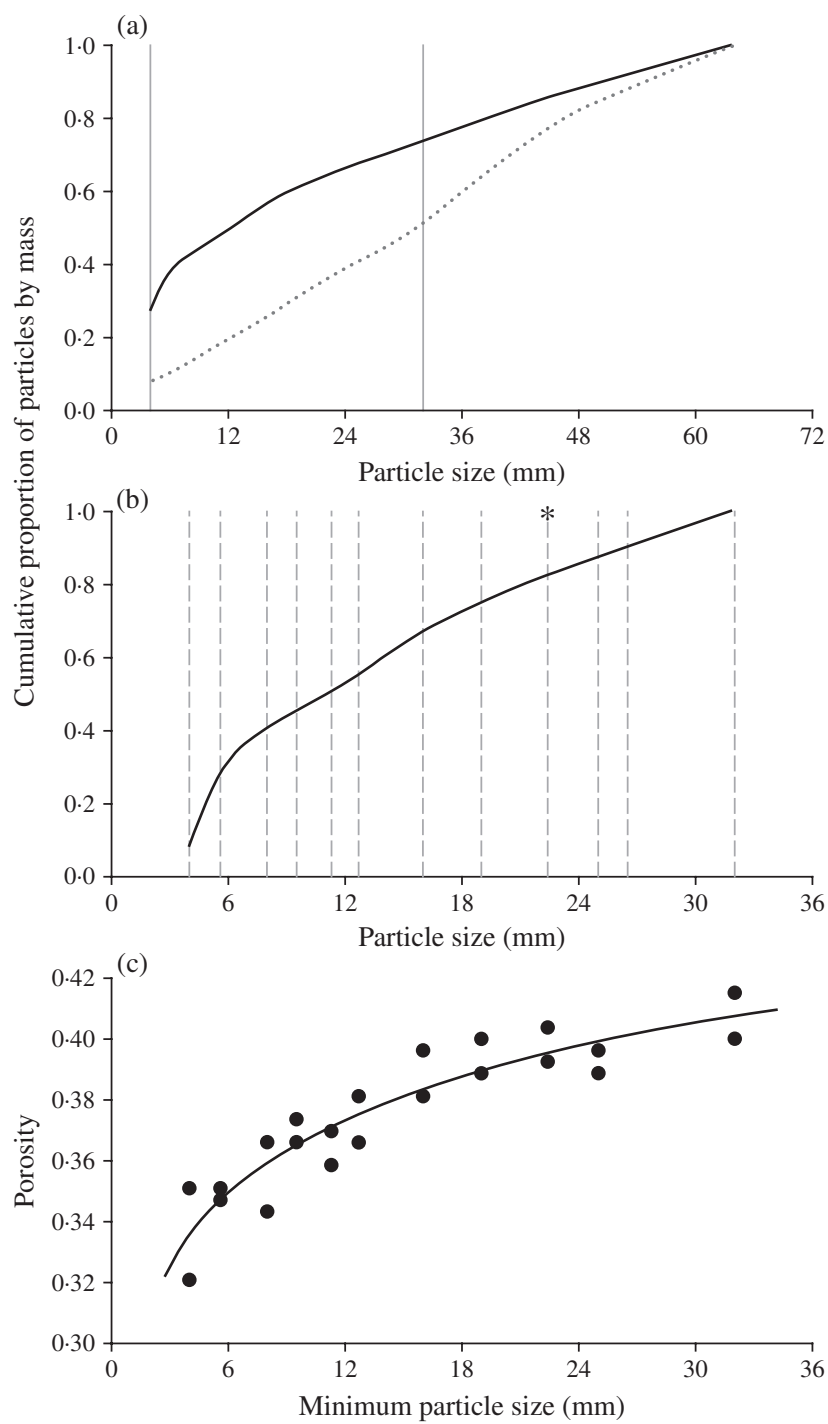

FIG. 1. (a) Distributions of sediment particle sizes (by mass) in the MRSHEP engineered reach (.....) and unenhanced habitat (__ of the Merced River. The range of particles used in experimental mixtures is denoted (__ ). (b) Particle size distributions of experimental sediment mixtures $\left(_{-}\right.$, , the minimum particle size of each treatment; *, the sediment mixture applied in the variable flow velocity experiment, with a minimum particle size of $22.4 \mathrm{~mm}$ ). The solid line represents the particle size distribution of unenhanced habitat as shown in Fig. 1(a). (c) Relationship between porosity and minimum particle size of experimental sediment mixtures. The curve was fitted by $y=0.0347 \ln x+0.29$.

daily during incubation and flow was manually adjusted to maintain interstitial velocities at the prescribed levels.

To complement the first experiment, the goal of the second experiment, the "variable sediment size' experiment, was to incubate embryos in sediments with different grain porosities and subject them to identical flow velocities among treatments. Sediment composition and corresponding porosity values are illustrated in Fig. 1(b), (c). These mixtures ranged 
TABLE I. Interstitial flow velocity and artificial redd sediment attributes of the treatments applied in the two experiments and trials. Each trial consisted of 12 different levels of treatment with one replicate per level of flow velocity or porosity

\begin{tabular}{lcr}
\hline Experiment and trial & Interstitial velocity attributes & Redd sediment attributes \\
\hline $\begin{array}{l}\text { Variable flow velocity } \\
\text { Trial 1 }\end{array}$ & $\begin{array}{r}\text { Range of } 0.05-1.00 \mathrm{~cm} \mathrm{~s}^{-1} ; \\
\text { increments of } 0.08 \mathrm{~cm} \mathrm{~s}^{-1} \\
\text { Range of } 0.18-2.35 \mathrm{~cm} \mathrm{~s}^{-1} ; \\
\text { increments of } 0.20 \mathrm{~cm} \mathrm{~s}^{-1}\end{array}$ & $\begin{array}{r}\text { All treatments consisted of a single } \\
\text { mixture with particles } \geq 22.4 \mathrm{~mm}\end{array}$ \\
Trial 2 & All treatments $0.45 \mathrm{~cm} \mathrm{~s}^{-1}$ & $\begin{array}{c}\text { Sediment among treatments ranged } \\
\text { from mixtures with } \geq 4 \text { to } \\
\text { Variable sediment size } \\
\text { Trial 1 }\end{array}$ \\
& & $\begin{array}{l}\geq 32 \mathrm{~mm} \text { particles; porosity values } \\
\text { ranged from } 0.30 \text { to } 0.37\end{array}$ \\
Trial 2 & All treatments $1.45 \mathrm{~cm} \mathrm{~s}^{-1}$ & \\
\hline
\end{tabular}

from particles distributed to mimic conditions in the un-restored reach of the Merced River and sieved to exclude particles $\geq 4$ and $\leq 32 \mathrm{~mm}$. The variable sediment size manipulation consisted of two trials: in the first, a velocity well within the bounds of measurements documented in the focal stream, $0.45 \mathrm{~cm} \mathrm{~s}^{-1}$, was applied. Because no effects were noted in the first trial, the velocity in the second trial was increased to a value well above any observed in the focal stream $\left(1.45 \mathrm{~cm} \mathrm{~s}^{-1}\right)$. Such a velocity range may reflect unrealistic environmental conditions, although interstitial velocities are rarely reported (particularly in gravel-enhanced rivers). These treatments were applied to determine if embryonic agitation could be induced under conditions theoretically possible in gravel-enhanced rivers. Discharge was recorded daily during incubation to ensure temporal consistency in flow velocity and adjusted when necessary.

\section{REDD CHAMBERS AND EXPERIMENTAL FACILITIES}

Artificial redds were housed in chambers constructed of polyvinyl chloride (PVC) and rubber (Fig. 2). Water was delivered through $1.3 \mathrm{~cm}$ diameter polyethylene tubing fixed to the centre of a $15.2 \mathrm{~cm}$ diameter rubber cap. A plastic gate valve was installed halfway along the intake tubing to help maintain flow and thus interstitial velocities at the prescribed

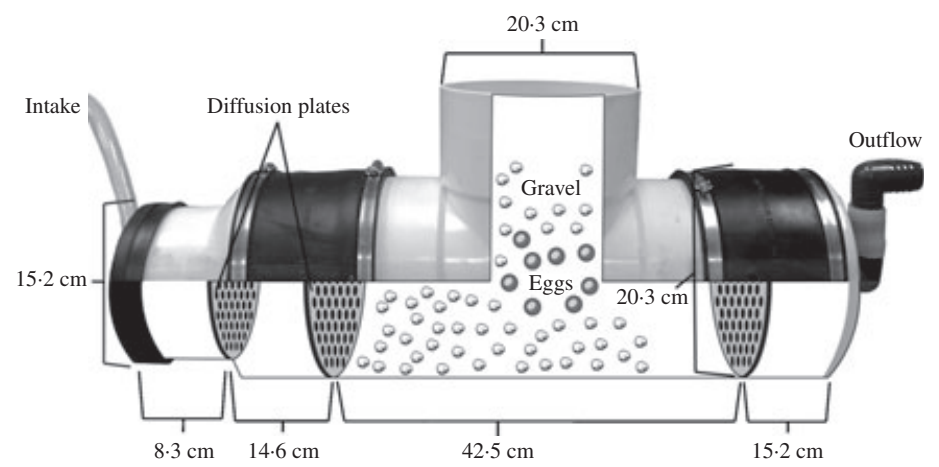

FIG. 2. Diagram of chambers that housed artificial Oncorhynchus tshawytscha redds during the experiment. 
levels. The intake cap was fitted (using a hose clamp) onto a PVC reducing component that expanded to a radius of $23.3 \mathrm{~cm}$. Prior to reaching the chamber centre, water travelled through two perforated plates that helped to diffuse flow. Plates were composed of $0.5 \mathrm{~cm}$ thick PVC sheets perforated with $0.5 \mathrm{~cm}$ diameter holes spaced $0.8 \mathrm{~cm}$ apart and a single layer of $18 \times 16$ mesh nylon screen fastened onto the plate using plastic bolts. A $23.3 \mathrm{~cm}$ diameter, $42.5 \mathrm{~cm}$ long PVC tee held $c .191$ of sediments where the $O$. tshawytscha embryos were buried during the experiment. After flowing through the gravel in the tee, water passed through a third diffusion plate and into a $23.3 \mathrm{~cm}$ diameter, $15.2 \mathrm{~cm}$ long PVC cap. Outflow pipes $3.2 \mathrm{~cm}$ in diameter were fitted into the centre of the cap. The three PVC components and diffusion plates were held together using rubber couplers fastened together with hose clamps. Outflow components were rotated to adjust water levels such that water remained $<2.5 \mathrm{~cm}$ above the lateral section of the tee but $>2.5 \mathrm{~cm}$ below the gravel layer to ensure that all flow was directed through the gravel.

Sediment used in artificial redds was collected from excess material from a spawning habitat augmentation project in the Merced River implemented by the California Department of Fish and Game. All gravel consisted of river-weathered particles removed from the Merced River downstream of the MRSHEP reach during mining operations. Treatments reflected the core samples taken from un-restored habitat of the Merced River and mixtures with incrementally increasing thresholds below which particles were excluded [Fig. 1(b)]. Sediments applied in experiments were vigorously rinsed in a perforated 191 bucket with water to remove all particles $<4 \mathrm{~mm}$ in diameter. Size classes were separated using brass and stainless steel sieves (Humboldt Manufacturing Corporation; www.humboldtmfg.com) with mesh sizes corresponding to the vertical dashes shown in Fig. 1(b).

To calculate porosity values for all sediment mixtures, a 191 bucket was filled to a 101 line, level with the sediment mixture of interest, the mass recorded, divided by $26 \mathrm{~kg}$ (the estimated mass of 101 of quartz with a density of $2.6 \mathrm{~g} \mathrm{~cm}^{-3}$ ) and one subtracted from this value to arrive at porosity [i.e. a dimensionless value that represents the proportion of interstitial space in a sediment matrix; Hornberger et al. (1998)]. Mean interstitial flow velocity through the pore spaces of the gravel was determined as: $\bar{v}=A \times Q \phi^{-1}$, where $A$ represents the crosssectional area of the tee $\left(324 \mathrm{~cm}^{2}\right), Q$ the total discharge moving through the apparatus and $\phi$ represents the porosity of the gravel mixture (Hornberger et al., 1998). Discharge (used to determine interstitial flow velocity) through the redds was checked daily by recording the amount of time required to fill a 50, 100, 500, 1000 or $5000 \mathrm{ml}$ beaker. The container used to measure discharge for a specific treatment corresponded to whichever one that took between 1 and $2 \mathrm{~min}$ to fill. If the recorded interstitial flow velocity varied from the intended level, the intake line gate valve was adjusted to increase or decrease flow rates through the redds and return interstitial velocities to the desired value.

The experiments were conducted at the Feather River Fish hatchery operated by the California Department of Fish and Game in Oroville, California ( $\left.39^{\circ} 31^{\prime} \mathrm{N} ; 121^{\circ} 33^{\prime} \mathrm{W}\right)$. Chambers used in the experiment were placed in one of the four $1.2 \mathrm{~m} \times 5.2 \mathrm{~m} \times 0.8 \mathrm{~m}$ fibreglass juvenile fish rearing troughs. Gravity-delivered water from nearby Lake Oroville for hatchery operations (including routine $O$. tshawytscha egg incubation that occurred concurrent with the experiments) was routed to an 8001 fibreglass reservoir tank positioned $1 \mathrm{~m}$ above the chambers. Discharge to each experimental unit was gravity head driven and flow to each unit was regulated using a PVC gate valve installed in the intake tubing. Water levels in the fish rearing troughs (originating from experimental unit effluent) were maintained at $c .8 \mathrm{~cm}$, or about half as tall as the experimental units, to buffer the redds from temperature fluctuations. Water quality over the course of the experiment was well suited for $O$. tshawytscha egg incubation: temperatures did not exceed $13.8^{\circ} \mathrm{C}$, fine sediments were filtered from inflows prior to reaching the reservoir trough as part of routine hatchery operations and DO levels remained $>9.6 \mathrm{ppm}$ (A. J. Dill, pers. comm.).

\section{EMBRYO INCUBATION AND RETRIEVAL}

Prior to embryo incubation, cavities were excavated approximately halfway to the bottom of the chambers by extracting c. 3.51 of sediment. On 6 October 2010 (trial 1) and 1 November 2010 (trial 2), embryos were obtained from two females that were fertilized with milt from 
two to three males following routine hatchery procedures. Each experiment and trial consisted of eggs from a single female. A plastic measuring cup was used to pour $60 \mathrm{ml}$ of fertilized embryos (c. 225 individuals) into the cavity of each redd. Embryos were dispersed throughout the chamber by generating gentle turbulence by hand and the extracted rocks were replaced once embryos were deposited. All embryos were buried within $0.5 \mathrm{~h}$ of fertilization. Each experiment was randomly assigned embryos from one of the two females. Four additional sub-samples of embryos from each female were incubated in the same juvenile rearing trough that held the experimental redds (control embryos) to (1) determine the mean count per $60 \mathrm{ml}$ scoop, (2) serve as survivorship estimates independent of experimental treatments and (3) allow developmental monitoring. Stacks containing control embryos shared the same water source as the experimental redds. Embryos were not directly counted prior to incubation because of the time and handling required.

Embryos were allowed to incubate for 25 days, at which point eyes had developed in all viable control individuals. Once salmonid embryos develop eyes, they become very robust to physical disturbance (Jensen \& Alderdice, 1983, 1989; Crisp, 1990) and it was therefore assumed that sensitivity to high interstitial flows would be minimal beyond this stage. Sediment was carefully removed from redd chambers by hand and recovered embryos with eyes were classified as surviving individuals. Eyeless, damaged or fungus-infected embryos were considered deceased. Severely degraded partial embryos were uncovered during excavation, suggesting that some embryos irrecoverably decayed over the course of the incubation period. Thus, survivorship was quantified from control batches rather than direct counts of embryos.

\section{DATA ANALYSES}

Estimated mean survivorship per redd was determined by dividing the number of recovered eyed embryos by the mean number of surviving control embryos from the respective female to account for variation in survivorship among lineages. Consequently, survivorship was proportional and theoretically bounded between 0 and 1 . Redd-specific survivorship was occasionally $>1$ when the number of recovered individuals exceeded the mean number surviving in control batches, which was caused by inherent variation in the number of embryos added to chambers (which was standardized per $60 \mathrm{ml} \mathrm{scoop}$ ).

Data from both trials of the variable flow velocity experiment were combined for analyses as all other potentially confounding factors (such as redd grain sizes) were held constant between trials. Trial data were analysed separately in the variable porosity experiment as flow velocity was increased (to a consistent level among treatments; Table I) between trials. Survivorship data were first relativized to the observed maximum of 0.975 and then logittransformed as: $\operatorname{logit}(S)=\ln \left[S(1-S)^{-1}\right]$, where $S$ represents survivorship. The logit transformation is appropriate for satisfying normality assumptions when proportional data are analysed using parametric statistics (Warton \& Hui, 2011).

To determine if porosity and flow velocity significantly influenced survivorship, the best fit among the five candidate models chosen a priori was determined first: linear, second-order polynomial, square root, logarithmic and exponential, relating the independent variables and logit-transformed survivorship. Models were compared using AIC comparisons for datasets with small sample sizes $\left(\mathrm{AIC}_{\mathrm{c}}\right)$. For the variable velocity experiment, models with trial and trial $\times$ independent variable interaction terms were initially assessed to determine if pooling data from both trials affected the experimental outcome. Terms that included trial number were removed if not statistically significant and models were subsequently reassessed. The model with the lowest AIC value in each experiment was statistically assessed using nonlinear least squares regression. All statistics were performed in R v. 2.13.1 (R Development Core Team; www.r-project.org).

\section{RESULTS}

Survivorship of control embryos was uniformly high. Mean proportional survivorship among all samples of control batch tray-reared embryos was 0.97 (range: 


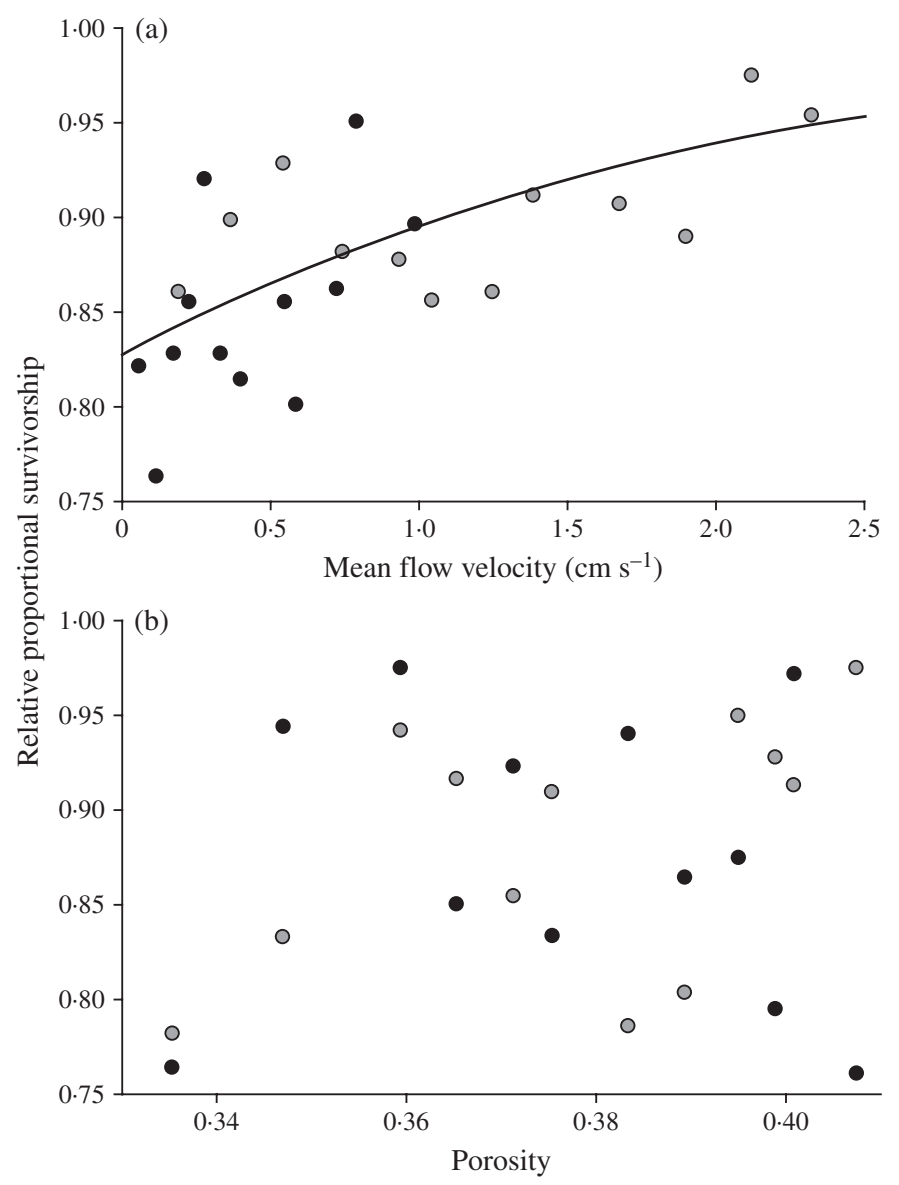

FIG. 3. Effect of (a) interstitial flow velocity (•, trial 1; O, trial 2) and (b) sediment size on estimated Oncorhynchus tshawytscha egg survivorship in artificial redds. All survivorship data were relativized to a maximum of 0.975 and logit-transformed for analysis. The relativized survivorship estimates are shown. Data from both trials of the variable flow velocity experiment were combined for analysis, while the variable porosity experiment trials were analysed separately as two different interstitial velocities [๑, trial $1\left(\bar{v}=0.45 \mathrm{~cm} \mathrm{~s}^{-1}\right)$; O, trial $\left.2\left(\bar{v}=1.45 \mathrm{~cm} \mathrm{~s}^{-1}\right)\right]$ were applied. (a) The curve was fitted by logit $y=0.58 x+1.57$.

0.94-0.98), thus embryos used in the experiment were viable. A statistically significant, positive relationship was detected between mean interstitial flow velocity and logit-transformed survivorship in the variable flow velocity experiment [Fig. 3(a) and Table II]. $\mathrm{AIC}_{\mathrm{c}}$ scores suggested that a linear fit was the most probable relationship. The trial and trial $\times$ velocity interaction terms were not statistically significant $(P>0.05$ in both cases). Survivorship among all treatments in the variable flow velocity experiment was generally high: untransformed values ranged from 0.84 to 1.08 (note that values $>1$ occasionally increased due to the variation in eggs added to chambers, all of which were compared to a single set of controls). Thus, increasing flow velocity in a coarse, porous substratum appears to confer a modest (15-24\%) but significant survivorship advantage to incubating $O$. tshawytscha embryos. 
TABLE II. Statistical parameters of non-linear least squares regression models relating Oncorhynchus tshawytscha embryonic survivorship to (1) interstitial flow velocity and (2) sediment porosity in artificial redds. Trials were combined for analysis in the variable flow velocity treatment because redd sediment structure was held constant between trials (initially included trial and trial $\times$ velocity terms were not statistically significant and therefore omitted)

\begin{tabular}{|c|c|c|c|c|c|c|}
\hline Experiment and trial & Independent variable & Selected model & $n$ & d.f. & $F$-value & $P$ \\
\hline \multicolumn{7}{|c|}{ Variable flow velocity experiment } \\
\hline Combined trials & Interstitial velocity & Linear & 24 & 1 & $17 \cdot 3$ & $<0 \cdot 001$ \\
\hline \multicolumn{7}{|c|}{ Variable sediment size experiment } \\
\hline Trial 1 & Porosity & $\begin{array}{l}\text { Second-order } \\
\text { polynomial }\end{array}$ & 12 & 1 & $0 \cdot 1$ & $>0.05$ \\
\hline Trial 2 & Porosity & Exponential & 12 & 1 & $0 \cdot 3$ & $>0.05$ \\
\hline
\end{tabular}

$n$, sample size.

In the variable sediment size manipulation experiment, neither of the trials revealed a relationship between porosity and logit-transformed survivorship [Fig. 3(b)]. Neither of the best-fit candidate models in trials 1 and 2 were statistically significant relationships $(P>0.05$ in both cases). Because the mean interstitial flow velocity was increased between trials, however, results between trials could be compared to determine if survivorship was elevated in redds with higher interstitial velocities (i.e. between trials). Data from both trials of the variable porosity experiment were pooled, remapped and logit-transformed to conduct a $t$-test comparing survivorship between trials. Survivorship in trial 2, during which flow was $c .1 \mathrm{~cm} \mathrm{~s}^{-1}$ greater in all treatments, was significantly higher relative to trial 1 ( $t=3 \cdot 4, P<0 \cdot 01)$. Therefore, varying the gradient of porosity of fines-free, porous substrata failed to elicit a response in embryonic survivorship, but both experiments suggested that elevating the interstitial flow velocity conferred a moderate survivorship advantage for $O$. tshawytscha embryos.

\section{DISCUSSION}

Results suggest that flow-induced salmonid embryo agitation does not occur in redds composed of porous substratum mixtures $(\geq 4$ and $\leq 32 \mathrm{~mm}$ ) with interstitial flow velocities $\left(\leq 2 \cdot 3 \mathrm{~cm} \mathrm{~s}^{-1}\right)$. Such environmental conditions are within or exceed the range of river habitats in California that have received gravel augmentation. Embryos exhibited slightly, but significantly greater survivorship, along a gradient of increasing flow velocity when incubating in uniformly porous substratum, while holding interstitial velocity consistently high and increasing redd substratum porosity induced no effect on survivorship. Therefore, hyporheic conditions in restored habitat with artificially deposited coarse substrata within the variables as applied in this experiment do not appear to result in flow-induced embryo agitation.

Findings at first glance appear to conflict with recent investigations that examined the role of interstitial flow velocity as a predictor of salmonid spawning habitat quality. Malcolm et al. (2011) concluded that interstitial velocity poorly predicted $S$. salar 
embryonic survival relative to DO concentrations, whereas $O$. tshawytscha survivorship increased moderately along a gradient of increasing flow velocity in this study. Most experimental and observational analyses of salmonid embryo survivorship have, however, considered embryos that were incubated in substrata with moderate to high concentrations of fine sediments and variable levels of DO. These are common conditions in most natal rivers, and such factors are often the principal concern for restoration (Kondolf, 2000; Greig et al., 2007). In contrast, interstitial water in habitats that have been augmented with gravel tends to carry high DO concentrations and reduced fines (Merz et al., 2004), which are the primary goals of augmentation. Results from previous studies suggest that interstitial flow velocity does not confer a survivorship advantage in settings where moderate to high levels of fine sediment play a strong role in limiting egg development (Malcolm et al., 2011). Results presented in this study suggest, however, that in environments with low finesediment loads, high interstitial flow velocity may generate moderate improvements in embryonic survivorship.

The mechanism elevating $O$. tshawytscha embryo survivorship along a gradient of interstitial flow velocity could not be determined from the current study findings alone. Redds with high interstitial flow velocities may have conferred moderately elevated DO concentrations, as these redds were subjected to faster rates of water turnover that replenished DO consumed by embryos and microorganisms in the incubation sediments. Elevated flow velocities typically increase DO concentrations in interstitial water (Greig et al., 2007). Unfortunately, DO was not monitored in this study because of the cost and logistic constraints involved in maintaining 24 DO sensors and because the study focus was on interstitial velocity. Alternatively, rapid flow velocities and associated turbulence may have limited mycelia development of the fungus Saprolegnia spp. from deceased to living embryos as observed in bluegill Lepomis macrochirus Rafinesque 1819 embryos subjected to fanning (Côte \& Gross, 1993), although a related phenomenon has not been demonstrated in salmonid redds.

Although a limited range of interstitial flow velocities and sediment mixtures were tested in this study, the range of values applied among treatments probably reflects conditions in $O$. tshawytscha spawning habitat, including restored settings. The majority of studies examining interstitial flow velocity in salmonid redds at c. $30 \mathrm{~cm}$ depth observed values below the maximum used in this study: most observed velocities were well below $1.0 \mathrm{~cm} \mathrm{~s}^{-1}$ (Greig et al., 2005; Zimmermann \& Lapointe, 2005; Carling et al., 2006). Malcolm et al. (2008) recorded c. $1.25 \mathrm{~cm} \mathrm{~s}^{-1}$ in a patch of engineered benthic habitat entirely lacking fines $(<4 \mathrm{~mm})$, while subsequent deposition of small particles over a 20 day period reduced the interstitial flow velocity to $<0.69 \mathrm{~cm} \mathrm{~s}^{-1}$. Although the median particle size of sediment mixtures used for creating or augmenting salmonid spawning redds usually exceeds $32 \mathrm{~cm}$, restoration mixtures usually contain some proportion of finer sediments (Zeh \& Dönni, 1994; California Department of Water Resources, unpubl. data). Other environmental factors may affect interstitial velocity within redds, such as slope, bed roughness, surface water velocity and hydraulic head. Few studies, however, have explicitly addressed interstitial velocity in salmonid redds relative to the number that have considered fine sediment concentrations, perhaps because of the inherent difficulty involved with measuring interstitial velocity (Porter et al., 2000). 
In conclusion, this study suggests that artificial gravel deposition used to improve $O$. tshawytscha spawning habitat does not induce physical agitation and consequential mortality to embryos. Rather, elevated interstitial flow velocities likely to be characteristic of restored habitat may confer a moderate survivorship advantage. The mechanism behind such trends remains speculative: higher rates of embryonic survivorship in redds with elevated interstitial flow velocities could be related to moderately higher concentrations of DO and decreased suitability for fungal growth. Managers undertaking restoration should consider high interstitial flow velocities as a moderately beneficial attribute of gravel augmentation projects rather than a potential source of physical agitation for salmonid embryos.

The authors thank A. J. Dill, A. Kastner and the entire staff at the Feather River Fish Hatchery for their extensive, generous support; A. Schroeder for assistance with redd chamber construction and gravel collection; B. Fletcher for construction assistance; the California Department of Fish and Game for providing salmon embryos and M. Gordon for assistance with graphical design. This study was funded by a grant from the Delta Stewardship Council, Delta Science Programme (\#U-05-SC-058).

\section{References}

Barlaup, B. T., Gabrielsen, S. E., Skoglund, H. \& Wiers, T. (2008). Addition of spawning gravel - a means to restore spawning habitat of Atlantic salmon (Salmo salar L.), and anadromous and resident brown trout (Salmo trutta L.) in regulated rivers. River Research and Applications 24, 543-550.

Bunte, K. \& Abt, S.R. (2001). Sampling surface and subsurface particle-size distributions in wadable gravel-and cobble-bed streams for analyses in sediment transport, hydraulics, and streambed monitoring. General Technical Report RMRS-GTR-74 . Fort Collins, CO: United States Department of Agriculture Forest Service.

Carling, P. A., Whitcombe, L., Benson, I. A., Hankin, B. G. \& Radecki-Pawlik, A. M. (2006). A new method to determine interstitial flow patterns in flume studies of sub-aqueous gravel bedforms such as fish nests. River Research and Applications 22, 691-701.

Côte, I. M. \& Gross, M. R. (1993). Reduced disease in offspring: a benefit of coloniality in sunfish. Behavioral Ecology and Sociobiology 33, 269-274.

Crisp, D. T. (1990). Some effects of application of mechanical shock at varying stages of development upon the survival and hatching time of British salmonid eggs. Hydrobiologia 194, 57-65.

DeVries, P. (1997). Riverine salmonid egg burial depths: review of published data and implications for scour studies. Canadian Journal of Fisheries and Aquatic Sciences 54, $1685-1698$.

Greig, S. M., Carling, P. A., Sear, D. A. \& Whitcombe, L. J. (2005). Refinement and application of a conductiometric standpipe technique for measuring interstitial flow velocity in salmonid spawning gravels. Hydrobiologia 545, 249-256.

Greig, S. M., Sear, D. A. \& Carling, P. A. (2007). A review of factors influencing the availability of dissolved oxygen to incubating salmonid embryos. Hydrological Processes 21, 323-334.

Harrison, L. R., Legleiter, C. J., Wydzga, M. A. \& Dunne, T. (2011). Channel dynamics and habitat development in a meandering, gravel bed river. Water Resources Research 47, $1-21$.

Honea, J. M., Jorgesen, J. C., McClure, M. M., Cooney, T. D., Engie, K., Holzer, D. M. \& Hilborn, R. (2009). Evaluating habitat effects on population status: influence of habitat restoration on spring-run Chinook salmon. Freshwater Biology 54, 1576-1592.

Hornberger, G. M., Raffensperger, J. P., Wiberg, P. L. \& Eshleman, K. N. (1998). Elements of Physical Hydrology. Baltimore, MD: The Johns Hopkins University Press.

Jensen, J. O. T. \& Alderdice, D. (1989). Comparison of mechanical shock sensitivity of eggs of five Pacific salmon (Oncorhynchus) species and steelhead trout (Salmo gairdneri). Aquaculture 78, 163-181. 
Jensen, J. O. T. \& Alderdice, D. F. (1983). Changes in mechanical shock sensitivity of coho salmon (Oncorhynchus kisutch) eggs during incubation. Aquaculture 32, 303-312.

Kondolf, G. M. (2000). Assessing salmonid spawning gravel quality. Transactions of the American Fisheries Society 129, 262-281.

Kondolf, G. M., Vick, J. C. \& Ramirez, T. M. (1996). Salmon spawning habitat rehabilitation on the Merced River, California: an evaluation of project planning and performance. Transactions of the American Fisheries Society 125, 899-912.

Lach, D. \& Duncan, S. L. (2006). Salmon 2100: The Future of Wild Pacific Salmon. Bethesda, MD: American Fisheries Society Press.

Malcolm, I. A., Grieg, S. M., Youngson, A. F. \& Soulsby, C. (2008). Hydrological influences on adult salmonid migration, spawning and embryo survival. In Salmonid Spawning Habitat in Rivers: Physical Controls, Biological Responses and Approaches to Remediation (Sear, D. \& DeVries, P., eds), pp. 249-274. Bethesda, MD: American Fisheries Society Press.

Malcolm, I. A., Youngson, A. F., Soulsby, C., Imholt, C. \& Fryer, R. J. (2011). Is interstitial velocity a good predictor of salmonid embryo survival? Transactions of the American Fisheries Society 140, 898-904.

Marshall, J. A., DeVries, P. \& Milner, N. (2008). Spawning habitat remediation as part of national and regional scale programs to recover declining salmon populations. In Salmonid Spawning Habitat in Rivers: Physical Controls, Biological Responses and Approaches to Remediation (Sear, D. \& DeVries, P., eds), pp. 275-300. Bethesda, MD: American Fisheries Society Press.

McNeil, W.F. \& Ahnell, W.H. (1964). Success of pink salmon spawning relative to size of spawning bed materials. USWFS Report Number 469. Corvallis, OR: United States Fish and Wildlife Service.

Merz, J. \& Setka, J. (2004). Evaluation of a spawning habitat enhancement site for Chinook salmon in a regulated California river. North American Journal of Fisheries Management 24, 397-407.

Merz, J. E., Setka, J. D., Pasternack, G. B. \& Wheaton, J. M. (2004). Predicting benefits of spawning-habitat rehabilitation to salmonid (Oncorhynchus spp.) fry production in a regulated California river. Canadian Journal of Fisheries and Aquatic Sciences 61, $1433-1446$.

Merz, J. E., Pasternack, G. B. \& Wheaton, J. M. (2006). Sediment budget for salmonid spawning habitat rehabilitation in a regulated river. Geomorphology 76, 207-228.

Pasternack, G. B. (2008). Spawning habitat rehabilitation: advances in analysis tools. In Salmonid Spawning Habitat in Rivers: Physical Controls, Biological Responses and Approaches to Remediation (Sear, D. \& DeVries, P., eds), pp. 321-348. Bethesda, MD: American Fisheries Society Press.

Porter, E. T., Sanford, L. P. \& Suttles, S. E. (2000). Gypsum dissolution is not a universal indicator of 'water motion'. Limnology and Oceanography 45, 145-158.

Ramstad, K. M., Woody, C. A. \& Allendorf, F. W. (2010). Recent local adaptation of sockeye salmon to glacial spawning habitats. Evolutionary Ecology 24, 391-411.

Rollinson, N. \& Hutchings, J. A. (2011). Why does egg size of salmonids increase with the mean size of population spawning gravels? Canadian Journal of Fisheries and Aquatic Sciences 68, 1307-1315.

Roni, P., Hanson, K. \& Beechie, T. (2008). Global review of the physical and biological effectiveness of stream habitat rehabilitation techniques. North American Journal of Fisheries Management 28, 856-890.

Ruckelshaus, M. H., Levin, P., Johnson, J. B. \& Kareiva, P. M. (2002). The Pacific salmon wars: what science brings to the challenge of recovering species. Annual Review of Ecology and Systematics 33, 665-706.

Warton, D. I. \& Hui, F. K. C. (2011). The arcsine is asinine: the analysis of proportions in ecology. Ecology 92, 3-10.

Zeh, M. \& Dönni, W. (1994). Restoration of spawning grounds for trout and grayling in the river High-Rhine. Aquatic Sciences 56, 59-69. 
Zimmermann, A. E. \& Lapointe, M. (2005). Intergranular flow velocity through salmonid redds: sensitivity to fines infiltration from low intensity sediment transport events. River Research and Applications 21, 865-881.

\section{Electronic References}

CDWR (2001). Merced River Habitat Enhancement Project Phase III - Robinson Reach: Engineering Report. Fresno, CA: California Department of Water Resources. Available at http://www.water.ca.gov/pubs/environment/restoration/merced_river_salmon_ habitat_enhancement_project_phase_iii_-_robinson_reach_engineering_report $/ \mathrm{mrs}$ hep3a.pdf/ (accessed May 2012).

Vogel, D. A. (2003). Merced River Water Temperature Feasibility Investigation Reconnaissance Report. Red Bluff, CA: Natural Resource Scientists, Inc. Available at http://www.fws.gov/stockton/afrp/documents/Merced_Temperature.pdf/

Vogel, D. A. (2007). A Feasibility Investigation of Reintroduction of Anadromous Salmonids above Crocker-Hoffman Dam on the Merced River. Red Bluff, CA: Natural Resource Scientists, Inc. Available at http://www.fws.gov/stockton/afrp/documents/Final_ Crocker_Huffman_Report.pdf/ 